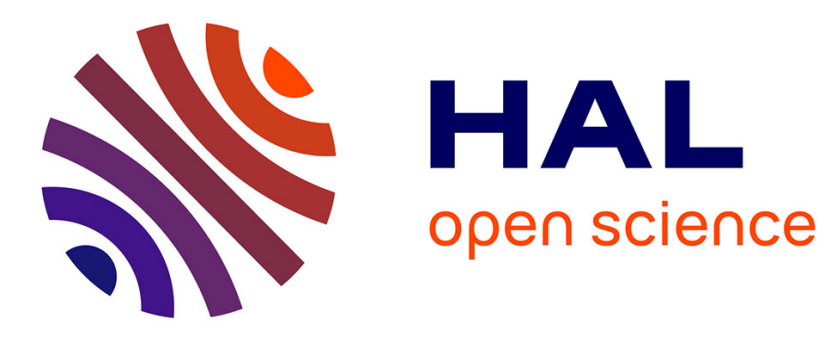

\title{
Health expenditure growth: reassessing the threat of ageing
}

Brigitte Dormont, Michel Grignon, Hélène Huber

\section{To cite this version:}

Brigitte Dormont, Michel Grignon, Hélène Huber. Health expenditure growth : reassessing the threat of ageing. Health Economics, 2006, 15 (9), pp.947-963. 10.1002/hec.1165 . halshs-00181605

\section{HAL Id: halshs-00181605 \\ https://shs.hal.science/halshs-00181605}

Submitted on 24 Oct 2007

HAL is a multi-disciplinary open access archive for the deposit and dissemination of scientific research documents, whether they are published or not. The documents may come from teaching and research institutions in France or abroad, or from public or private research centers.
L'archive ouverte pluridisciplinaire HAL, est destinée au dépôt et à la diffusion de documents scientifiques de niveau recherche, publiés ou non, émanant des établissements d'enseignement et de recherche français ou étrangers, des laboratoires publics ou privés. 


\section{Health expenditure growth : reassessing the threat of ageing}

Brigitte DORMONT* Michel GRIGNON`and Hélène HUBER ${ }^{\ddagger}$

July 6th, 2006

We are grateful for helpful comments from Jan Erik Askildsen (University of Bergen), Chantal Cases (IRDES), John N. Lavis (McMaster University), Michel Lubrano (University of Marseille), Dominique Polton (CNAmts) and Catherine Sermet (IRDes). We also thank the participants of the Fourgeaud, Legos, Ined and DeLta seminars in Paris and of the IEMS seminar (University of Lausanne) as well as the participants of the fourteenth European Workshop on Econometrics and Health Economics (Dublin) for useful comments. We also wish to thank two anonymous referees whose comments helped us to improve the paper. We are also grateful to IRDES for access to the data and numerous fruitful discussions about the definition of the morbidity indicators. Any errors are our responsibility.

*LEGOS, Université Paris Dauphine, Place du Maréchal de Lattre de Tassigny, 75775 Paris Cedex 16, France and IEMS Lausanne, Switzerland - brigitte.dormont@dauphine.fr

†Departments of Economics and Gerontology, McMaster University, Kenneth Taylor Hall, Hamilton, Ontario, Canada - grignon@mcmaster.ca

‡THEMA, Université Paris 10, 200, avenue de la République, 92001 Nanterre Cedex, France - helene.huber@uparis10.fr 


\section{Introduction}

For any developed country, an increase in the proportion of the elderly entails an increase in per capita health care expenditure. This is undoubtly true, given that individual health care expenditure is an increasing function of age. But what is the magnitude of this effect in comparison with other drivers of health care expenditures?

In this paper, we use micro data to evaluate the respective effects of demographic change, changes in morbidity and changes in practices on the growth in health expenditure that occurred in France between 1992 and 2000. The time span we consider for our retrospective analysis is rather limited. However, a non-negligible ageing of the population is observed during that period, at a pace which is representative of what is expected for the future.

The consequences of ageing is an issue addressed by numerous macro and micro-economic papers. At the macro-economic level, the vast majority of studies find that age structure has a small or non significant impact on health care expenditures, whereas GDP has a sizeable and highly significant impact [1-8]. At the individual level, micro-economic studies find as well that the influence of age on health care expenditure is significantly reduced when proximity to death is taken into account [9-13] - Recently, the OECD [14] provided retrospective decompositions of the growth in public health care spending, together with projections for 2050. For the OECD countries taken as a whole, the age effect accounted for less than one tenth of the growth in health care expenditure observed between 1970 and 2002. As for projections, the authors underline that non-demographic factors, including changes in technology, are the most important drivers in the projected increase. For the OECD countries,

the share of health expenditure in GDP is forecast to increase by 3.9 percentage points (from $5.7 \%$ in 2005 to $9.6 \%$ in 2050), of which 0.7 percentage point only is attributable to demographic effects.

Earlier projections of future health care expenditures simulated the impact of ageing simply by applying demographic projections to the observed profile of health expenditure by age group. However, changes in health care expenditure level also depend on changes of this profile over time [15, 16]. Graph 1 displays the profiles computed on our French database for years 1992 and 2000. Age group 0 corresponds to people age 0-9, age group 10 to people age 10-19, and so on, until age group 70, which is related to people age 70 and over. As expected, expenditures increase with age. The main feature, however, is that a sizeable upward drift of the profile is observed between 1992 and 2000. This drift may be related to changes in health status at a given age. It may also be linked to 


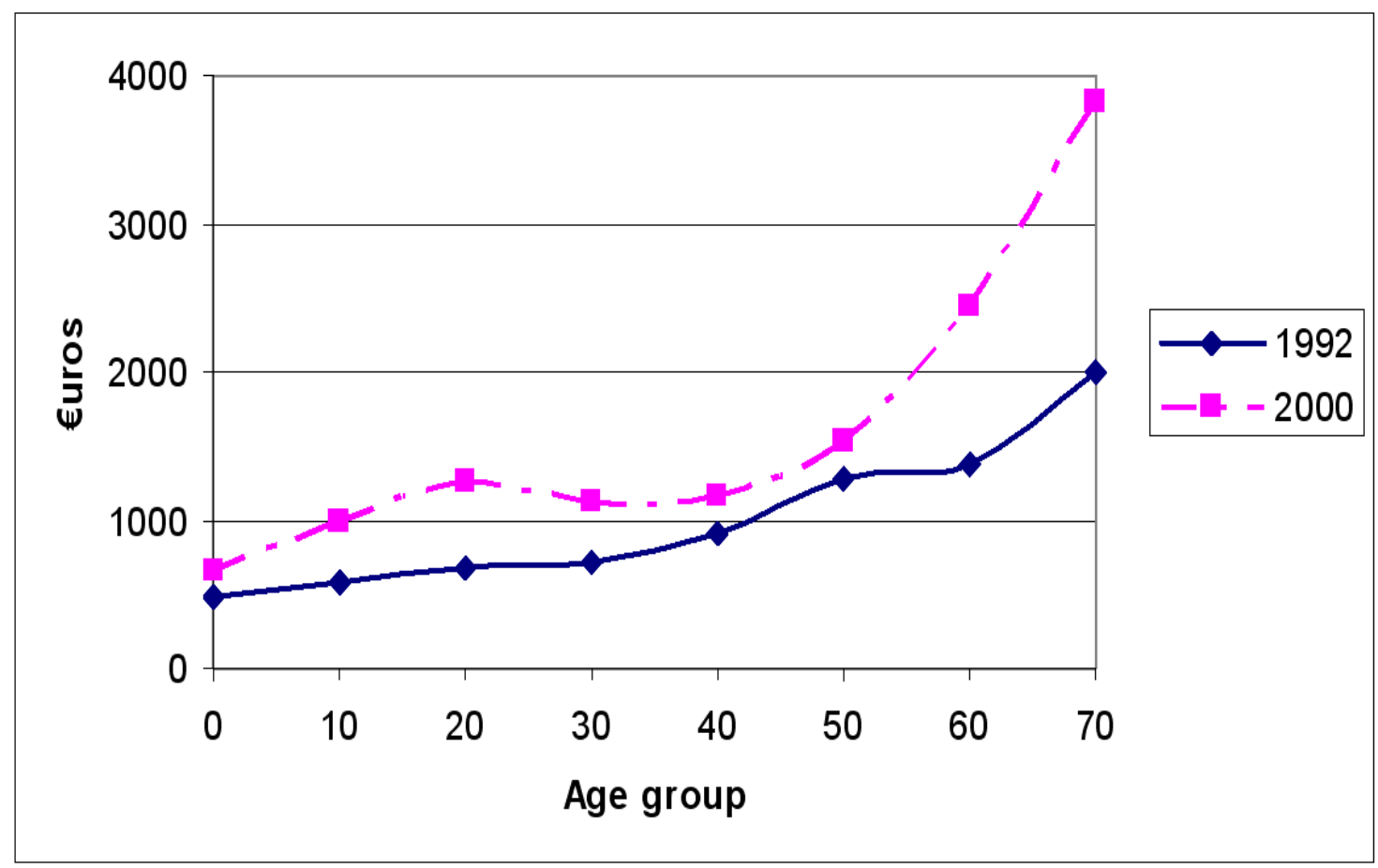

Graph 1: Average individual health care expenditures by age group, years 1992 and 2000

technological progress or more broadly to changes in practices, for a given age and a given morbidity.

Beyond the pure demographic effect, the upward drift of the age profile is likely to be the main driver of health care expenditure growth. In addition, it is of major importance to identify the causes of this drift, i.e. the respective impacts of technological progress and of changes in morbidity.

Trying to forecast how health status by age might evolve in the future is a rather hazardous enterprise. A plentiful literature has examined how increases in longevity could influence the population's health status. Various hypotheses have been considered, the two extreme ones being "expansion of morbidity" [17] and "compression of morbidity" [18]. Several intermediate hypotheses can be considered, with mixed situations and transition regimes regarding potential changes in illnesses and disability [19]. At the macroeconomic level, a rough assessment is in general built on the basis of the projected increase in longevity. For instance, the "healthy ageing" hypothesis comes down to assuming that gains in longevity are gains in healthy years. At the microeconomic level, the Future Elderly Model, a microsimulation model built by the Rand, uses estimated transition rates to simulate changes in health status and deaths for Medicare enrollees [20,21].

Evaluating the effects of technological progress or changes in behavior is not easier. Evans et al. [22] show that projections performed in the 70's or in the 80's greatly overstate the number 
of acute hospital days actually observed in 2000, and underestimate the use of physicians' service. At the microeconomic level, available studies generally focus on a limited number of illnesses and procedures, such as hip replacement or treatment for heart attack [23, 24]. The macroeconomic projections performed by the OECD [14] allow for "non-demographic" factors by simply assuming that health care expenditures grow $1 \%$ per annum faster than income, an assumption in keeping with the trends observed over the past two decades.

To sum up, identifying the factors that influence the age profile of health care expenditures is a difficult undertaking, which deserves further investigation. The purpose of this paper is to add a contribution to this open question by proposing an original microsimulation method for analysing changes over time in the age profile. This method makes it possible to separately identify changes that are due to changes in morbidity on the one hand, and to changes in practices on the other.

As regards morbidity, we consider a vector of chronic illnesses and disability indicators and allow for the changes in prevalence by age that are observed over time for each illness or disability level. Our estimation enables us to compute the resulting impact of all these changes on expenditures by age. On the whole, this provides an accurate assessment of the total impact of changes in morbidity on expenditures.

Our microsimulation method captures changes in practices through changes in the coefficients which measure the influence of morbidity on health care use. This allows us to observe for each given illness whether health care expenditure is higher in 2000 than 1992. We thus capture a much broader phenomenon than technological progress. Our method makes it possible to embrace changes in patients' preferences and physicians' behavior as well as the impact of technological progress. All these components are to be considered in order to provide a convincing decomposition of health care expenditure growth.

Our data is a representative sample of 3,441 and 5,003 French individuals observed in 1992 and 2000. We apply our microsimulation approach to identify the components of the drift observed between 1992 and 2000 in the age profile of health expenditures. Our results show that changes in morbidity induce a downward drift of the health care expenditures profile, whereas the drift due to changes in practices is upward and sizeable.

Once we have evaluated the respective influences of changes in morbidity and changes in practices at the microeconomic level, we apply our results to the age structure of the French population in order 
to compare the aggregate effects of demographic change and profile drifts for the period 1992-2000. At this macroeconomic level, the rise in health care expenditures due to demographic change is very small, in comparison with the effects of changes in practices. For total expenditures, we find that the impact of changes in practices is 3.8 times larger than the rise in health care expenditures due to change in the age structure of the population.

In comparison with studies focusing on time to death [9-11,13], our database presents the advantage of providing information about many morbidity indicators, in addition to death proximity ("death risk"). Furthermore, rather than studying only hospital expenditures or aggregate individual expenditures [9-11], our dataset allows us to study the different components of individual health care expenditures: home and office physician visits, pharmaceutical expenditures, and hospital expenditures. Such a detailed analysis lets us account for the very different nature of these expenditure components. For example, pharmaceutical and hospital costs are much influenced by technological progress, unlike physician visits.

The paper is organized as follows. The next section presents the microsimulation method. In section 3, we present the sample and give some information about the French health care system. Then, we carry out a descriptive analysis of the data. The results of our microeconometric estimates and simulations are commented on in section 4 . In section 5 , we conclude by using our microsimulation outcomes to compare the aggregate impacts of demographic effects and changes in profiles at the macro level.

\section{The microsimulation method}

Our empirical approach entails several steps: we first specify and estimate a model explaining the decision to consume health care and the level of expenditure, conditional on that decision; we run the model separately on data for 1992 and 2000. Then, we use the estimated coefficients to simulate counterfactual average levels of participation and expenditure by age group: this allows us to disentangle the effects of changes in morbidity and changes in practices in the profile drift observed between 1992 and 2000. Finally, we use the simulated expenditure profiles to identify, at the macroeconomic level, the respective impacts on expenditure growth of demographic change, changes in morbidity, and changes in practices for a given morbidity. These steps are followed separately for each type of 
service: inpatient, physicians and prescription drugs.

\section{$2.1 \quad$ The model}

We use a two-part model, first explaining the decision to consume health care, then explaining the level of health care expenditures for participants. Such models are particularly appropriate in the econometric analysis of individual health care expenditures. Indeed, a non-negligible proportion of people do not use health services at all during a given year (about 10\%), this proportion being much higher as regards hospital (about 90\% of non-users). Our decision to consider Log-transformed expenditures is explained below, while our decision to use a model assuming independence between participation and level of expenditure is discussed in subsection 2.3.

Consider individual $i$ belonging to age group $j . P_{i j}$ is the dichotomic variable for participation and $C_{i j}$ the health care consumption. We consider the following two-equation model:

$$
P_{i j}=\mathbf{I}_{P_{i j}^{*}>0} \quad \text { with } \quad P_{i j}^{*}=W_{i j}^{\prime} c+M_{i j}^{\prime} b+a_{j}+u_{i j}=X_{1, i j}^{\prime} d+u_{i j},
$$

where $u_{i j} \sim N\left(0, \sigma^{2}\right)$.

$$
\left\{\begin{array}{l}
C_{i j}=\mathbf{I}_{\left(P_{i j}=1\right)} \cdot\left[C_{i j}^{*}\right] \\
\text { with } E\left(C_{i j}^{*} \mid X_{2, i j}^{\prime}\right)=\exp \left(Z_{i j}^{\prime} \gamma+M_{i j}^{\prime} \beta+\alpha_{j}\right)=\exp \left(X_{2, i j}^{\prime} \delta\right)
\end{array}\right.
$$

Equation (1) describes the decision to use health care services and equation (2) the level of consumption.

We decided to use for (2) a log link relationship: $E\left(C_{i j}^{*} \mid X_{2, i j}^{\prime}\right)$ is defined as an exponential function of $X_{2, i j}^{\prime} \delta$. Indeed, the non-zero observations for health expenditures are highly skewed (the skewness varies between 4.50 and 15.47 on our data, depending on the year and type of expenditure considered). Taking the $\log$ transformation reduces the skewness to values between -0.26 and 0.01 . In addition, we used for $C_{i j}^{*}$ a gamma distribution, which enables us to take heteroskedasticity into account. The choice of a gamma distribution is based on the outcomes of Park tests that we performed following the approach suggested by Manning and Mullahy [25].

$X_{1, i j}^{\prime}$ and $X_{2, i j}^{\prime}$ are the explanatory variables of the participation and consumption equations. These regressors entail dummies $a_{j}$ and $\alpha_{j}$ related to the age groups and morbidity indicators $M_{i j}^{\prime}$. In 
addition, equations (1) and (2) include explanatory variables (variables $W_{i j}^{\prime}$ or $Z_{i j}^{\prime}$ ) relative to socioeconomic characteristics of the individual [26]. The potential list of morbidity indicators includes disability, death risk, the number of illnesses, self-assessed health, and indicators for the following illnesses : diabetes, chronic obstructive pulmonary disease and related diseases, ischemic heart disease, hypertension, circulatory disease, conditions associated with lipid metabolism, depression, sleeping disorder, cataract, and arthritis, arthropathy and/or back pain. The potential list of socio-economic characteristics includes level of earnings, social and occupational group, education level, coverage by a complementary insurance, gender, family size and matrimonial status. The list actually used depends on the equation considered ((1) or (2)) and of the type of expenditure (ambulatory care, pharmaceutical or hospital expenditure): it has been set by a careful selection process. Significant variables were selected for each type of expenditure and for each equation of the model; among the selected variables, those whose exogeneity seemed questionable were tested (synthetic morbidity indicators and complementary coverage) and only those that proved to be exogenous were selected (see section 2.3).

The morbidity indicators we use are quite comprehensive: they provide a multidimensional description of every individual's health status. Morbidity is the only factor explaining the increasing pattern of the health care expenditure profile: when controlling for morbidity level, we have found that health expenditure is no longer increasing with age [27].

Recently, a great number of studies suggested that time to death was the main factor explaining the shape of the profile [9-11]. As a matter of fact, time to death could be interpreted as an indicator of morbidity, whose exogeneity could be questioned [28]. Our database provides us a proxy of time to death (the Death Risk indicator) and very detailed information about chronic illnesses and disability. Thus, we capture health status with more accuracy than with taking time to death only. Furthermore, we are able to test for the exogeneity of our indicators.

\subsection{Predictions and microsimulations}

We perform simulations on participation and consumption behavior.

The decision to use health care services is easily predicted from the estimation of (1) by a Probit 
estimator:

$$
\hat{E}\left(P_{i j} \mid X_{1, i j}\right)=\Phi\left(X_{1, i j}^{\prime} \hat{d}\right)
$$

with $\Phi($.$) standing for the cdf of the standard normal distribution.$

As concerns expenditures for health care users, the GLM specification leads to a direct estimate of the conditional expectancy of expenditures on the raw scale:

$$
\stackrel{\wedge}{E}\left(C_{i j} \mid P_{i j}=1 ; X_{2, i j}\right)=\exp \left\{X_{2, i j}^{\prime} \hat{\delta}\right\}
$$

The model is estimated separately for years 1992 and 2000 for each type of expenditures (consultations, pharmaceutical and hospital expenditures), leading to estimated coefficients $\hat{d}_{92}, \hat{d}_{00}, \hat{\delta}_{92}$ and $\hat{\delta}_{00}$.

Since the computation of predictors (3) and (4) involve several non-linear functions, we cannot exhibit additive effects. We use instead an incremental approach. As concerns the decision to use health care services (participation), we compute the predicted probability for the average patient of each age group $j$. This is done for each expenditure component, i.e. physicians visits, drugs and hospital.

For individual $i$ belonging to age group $j$ and observed in 1992, the predicted probability of using health care services is the following:

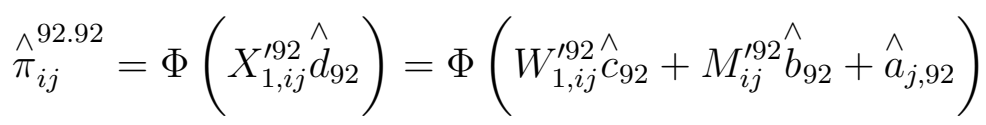

For the purpose of our simulations, we evaluate this probability at the average point of each age group $j$ :

$$
\stackrel{\wedge}{\pi}_{. j}^{92.92}=\Phi\left(X_{1, . j}^{\prime 92} \hat{d}_{92}\right)=\Phi\left(W_{1, . j}^{\prime 92} \hat{c}_{92}+M_{. j}^{\prime 92} \hat{b}_{92}+\hat{a}_{j, 92}\right)
$$

We have chosen this approach instead of computing the average by age group of individual predicted probabilities. This empirical strategy allows us to simulate the effects of changes in morbidity, while we hold constant the other explanatory variables.

We focus on changes in morbidity and changes in practices, for a given morbidity. The effect on participation of changes in practices for a given morbidity is assessed by replacing $\hat{b}_{92}$ by $\hat{b}_{00}$ in expression (5):

$$
\stackrel{\wedge}{\pi}_{. j}^{m 92 . b 00}=\Phi\left(W_{1, . j}^{\prime 92} \hat{c}_{92}+M_{. j}^{\prime 92} \hat{b}_{00}+\hat{a}_{j, 92}\right)
$$


The incremental effect of changes in morbidity between 1992 and 2000 is assessed by replacing, for each age group $j$, the average level of morbidity observed in $1992, M_{. j}^{\prime 92}$ by the average level of morbidity observed in $2000, M_{. j}^{\prime 00}$ :

$$
\stackrel{\wedge}{\pi}_{. j}^{m 00 . b 00}=\Phi\left(W_{1, . j}^{\prime 92} \hat{c}_{92}+M_{\cdot j}^{\prime 00} \hat{b}_{00}+\hat{a}_{j, 92}\right)
$$

Finally, the incremental effects of other changes in behavior and individual characteristics lead to the predicted probability for the year 2000:

$$
\stackrel{\wedge}{\pi}_{\cdot j}^{00.00}=\Phi\left(X_{1, . j}^{\prime 00} \hat{d}_{00}\right)=\Phi\left(W_{1, . j}^{\prime 00} \hat{c}_{00}+M_{. j}^{\prime 00} \hat{b}_{00}+\hat{a}_{j, 00}\right)
$$

We used expression (4) and followed the same principles to compute the predictions of the levels of expenditures by age group for health care users: $(C \mid P)_{. j}^{92.92},(C \mid P)_{. j}^{m 92 . b 00},(C \mid P)_{. j}^{m 00 . b 00}$ and $(C \mid P)_{. j}^{00.00}$. More precisely, the means by age group of the explanatory variables are computed only on the subsamples of participants, when simulating the conditional expenditures.

The same simulations are computed for participation, consumption of health care users and unconditional consumption. Taking the example of the consumption of health care users, one has :

- The transition from $(C \mid P)_{. j}^{92.92}$ to $(C \mid P)_{. j}^{m 92 . b 00}$ gives the effect of changes in practices for a given morbidity.

- The transition from $(C \mid P)_{. j}^{m 92 . b 00}$ to $(C \mid P)_{. j}^{m 00 . b 00}$ gives the incremental effect of changes in morbidity (among the participants) between 1992 and 2000.

- Finally, the transition from $(C \mid P)_{. j}^{m 00.600}$ to $(C \mid P)_{. j}^{00.00}$ gives the incremental effect of other changes in behavior and individual characteristics between 1992 and 2000.

Broadly understood, changes in practices are measured by changes in the estimated parameters of (1) or (2) between 1992 and 2000. These changes are linked to changes in patients' or physicians' behavior. They also result from technological progress, which induces the use of more costly innovative drugs and procedures. It may concern as well the extension of innovative procedures and prevention protocols to old ages. For example, the use of surgical treatment of cataract changed dramatically for people age 75-84 in France: it rose from 40 \% to 55 \% between 1993 and 1998 [29]. Another example is the increasing use of angioplasty for the treatment of Acute Myocardial Infarction. In France, the 
proportion of treatment by angioplasty rose from $9.6 \%$ in 1993 to $22 \%$ in 2001 for people age 75 84 [30]. The increasing use of these procedures is observed in comparable developed countries [31]. It stems, on the demand side, from changing preferences towards a better well-being of the elderly. On the supply side, it derives from technological progress, which leads to better outcomes and improved safety. This allows the extension of innovative procedures to older people. This might indeed raise costs, but it also improves well-being for the elderly considerably.

We capture changes in practices for a given morbidity with changes in the estimated coefficients

$\hat{b}$ and $\hat{\beta}$, which measure the influence of morbidity on participation rate and expenditures. What we call "other changes in behavior and individual characteristics between 1992 and 2000" can also be interpreted as changes in practices. They depend on changes in the variables $W$ and $Z$, as well as changes in the parameters $\hat{c}, \hat{\gamma}, \hat{a}_{j}$ and $\hat{\alpha}_{j}$. For the sake of simplicity, we present the effects of changes in the age-specific constants in the last table only. These changes in age-specific constants can be linked to changes in unobservable morbidity and to changes in practices for a given level of morbidity.

Notice that our microsimulation method is in the spirit of the Oaxaca methodology [32]. It has been recently extended to study income distribution in developing countries [33] and used to analyse the process of technological progress diffusion within French hospitals [34].

\subsection{Estimation methods}

A typical feature of health expenditure data is that many individuals incur no health cost within the period of observation. Such a configuration requires specific estimation techniques. Many papers addressed the issue of the choice between the sample-selection model (Heckit [35]) and the two-part model [36-38]. Monte Carlo studies implemented by Manning, Duan and Rogers [38] show that the two-part model may perform better than the sample selection model even when the latter is the true model. Leung and $\mathrm{Yu}$ [37] have shown that the performances of the sample selection model depend crucially on the degree of collinearity between the inverse Mill's ratio and the explanatory variables in the second step equation. When there is no collinearity, a t-test of the coefficient of the inverse Mill's ratio can be used to choose between the two specifications. When there is collinearity, the two-part model is more reliable because it performs better than the sample-selection model in terms of mean-squared error. 
Our data is characterized by a high correlation between the inverse Mill's ratio and the explanatory variables of the second step equation: the correlation coefficient lies between 0.85 and 0.87 , depending on the health expenditure component considered. We thus chose the two-part model. This model presents another advantage: it permits the use of a generalized linear model estimator (GLM) to estimate the level of consumption, conditional on participation. The GLM makes it possible to deal rather easily with other typical features of health consumption data, such as skewness in the rawscale variable, heavy-tailed distributions and heteroscedastic errors. Indeed, it makes it possible (i) to avoid the retransformation difficulties by specifying directly the expectancy of expenditure instead of the $\log$ of expenditure, (ii) to allow for heavy-tailed distributions and heteroscedastic errors by considering Poisson or Gamma distributions for the dependent variable [25].

Some morbidity indicators may be non exogenous. Chronic diseases are likely to be exogenous: they cannot be cured and their onset is independent from the amount of medical care provided. But this is not the case for disability and synthetic indicators of health status, such as death risk, self-assessed health and number of diseases. Coverage by a complementary insurance may also be non exogenous, since it results partly from a decision of the individual. We have chosen to select only exogenous regressors to avoid adding methodological difficulties to an already rather sophisticated empirical approach. Exogeneity tests have thus been performed for the following variables: coverage by a complementary insurance, death risk, self-assessed health, disability and number of diseases [27].

Thanks to the richness of our data, we were able to perform Hausman tests for each type of health care consumption (consultations, pharmaceutical and hospital expenditures). This was possible for year 2000 only. Instruments used were head of household status (working, unemployed, non-working, the reference being retired), a dummy indicating whether the individual is a smoker, another dummy indicating whether he/she receives minimum benefit payment, height, BMI. Not enough instruments were available for 1992, when the survey did not record enough information about socioeconomic variables nor about individual characteristics and habits. Nevertheless, it seems to us legitimate to assume that exogeneity checked for 2000 holds for 1992.

We used intrumental variables to build a Hausman specification test for each of the three types of health care consumption (detailed procedures are described in [27]). A Sargan test was used to check the validity of the instruments used. In addition, we examined whether this test could be subject to the weak instrument problem [39]. We found a large significance of the partial correlation between 
instruments and morbidity indicators, with high statistics and levels of significance lower than $10^{-3}$. Sargan tests validated the instruments' exogeneity. Coverage by a complementary insurance appear to be exogenous for consultations and pharmaceutical expenditures (it is not a significant regressor for hospital). Exogeneity is rejected for disability as regards consultations expenditures and for death risk as regards pharmaceutical expenditures.

\section{Data}

\subsection{The dataset}

We make use of a micro-economic data set concerning 3,441 insured French citizens for the year 1992 and 5,003 for the year 2000. This data set results from a survey (Santé Protection Sociale) conducted by IRDES (Institute for Research and Information in Health Economics, Paris) on a subsample drawn from administrative data (Echantillon Permanent d'Assurés Sociaux) provided by the French public health insurance, which records every health expenditure submitted to reimbursement by subscribers.

The sample gives reliable information about each individual's health care expenditures, the subscription to a complementary insurance coverage, morbidity and socio-demographic characteristics such as age, social and occupational group and net income. The sample is composed of people living in regular households. Therefore, it does not provide an appropriate information about long-term care, which is out of the scope of this paper. Between 1992 and 2000, the use of institutionalization has remained stable. Thus it is not likely to affect our results. Although of a reasonable size, our sample is not large enough to record numerous observations for the individuals aged 80 and more. We thus cannot consider separately an age group corresponding to the oldest old. We have defined age groups from 0 to 69 with ten-year intervals, and a last group for individuals age 70 and over.

Individual physician and pharmaceutical expenditures are directly observed by the public health insurance. Hospital expenditures are evaluated at the individual level by the health insurance administration on the basis of the individual's recorded length of stay and of the average daily cost of stay in the corresponding care unit.

In order to make health care expenditures comparable between years 1992 and 2000, we adjusted the observed expenditures for inflation and converted all values to Euros. The price index [40] is 
specific to the type of expenditure of interest. Between 1992 and 2000, the computed price index of physician consultations rose by $9.15 \%$, reflecting changes in fee levels, which are mostly regulated. The price index of ambulatory pharmaceutical expenditures rose by $2.04 \%$. It does not reflect the price of innovations, which are not included in this index. The price index of hospital expenditures rose by $16.54 \%$. Like the pharmaceutical expenditures price index, it does not include technological progress. Indeed, the daily cost of stay in each care unit is computed on the basis of the use of doctors' and nurses' work (duration and intensity of care), together with a combination of the index of civil servants' wages and price index of regular goods.

Therefore, we simply adjust for the general inflation rate. The growth of adjusted health care expenditures we want to analyze is still influenced by the pace of technological progress, which we are precisely interested in.

\subsection{The French health care system}

The French health insurance system is public and universal. About $99 \%$ of the population is covered, without age restriction: coverage is continuous over the entire life span. It also grants unlimited access to care, without frequency restrictions, at least for the period under study. Consultations for ambulatory care are initiated by the patient. But the level of drug consumption is decided on by the physician through prescriptions. In France, specialist consultations mostly take place in ambulatory care and not within hospital. Until 2006, patients had free access to specialists. The public insurance system covers almost $100 \%$ of hospital care expenditures and $70 \%$ of expenditures for ambulatory care. A large majority - 80\% - of the population has complementary insurance. It may result from a decision of the individual, but is more often provided by the employer. Complementary insurance reimburses the remaining $30 \%$ of ambulatory care expenditures. Ambulatory care coverage includes pharmaceutical expenditures. This contrasts strongly with other systems, such as Medicare in the US or public coverage in many provinces of Canada. In 2000, Medicare in the US did not cover medication when it was not prescribed in hospital. In France, the overall value of drug prescriptions is growing rapidly because of the rising prices of innovations newly allowed on the market. On the whole, between 1992 and 2000, total pharmaceutical expenditures increased by 59\% in volume, whereas the total number of physicians' visits increased by $18 \%$ [40].

In France, physicians in the ambulatory care sector are mostly self-employed and paid on a feefor-services basis. Hospitals are public (2/3 of stays) or private (for profit or not-for-profit). Patient 
selection is forbidden in the public sector. The use of high tech innovative procedures mostly take place in teaching hospitals, which are public. Until 2004, public hospitals and some private not-forprofit hospitals were regulated through a global budget system. Other private hospitals were paid on a fee-for-service basis. For the period under study, there is no reason for rationing in access to care for the elderly. Indeed, in addition to the fact that selection is not allowed in the public sector, the global budget payment system does not provide incentives to reject patients with complications or comorbidities. As concerns ambulatory care and hospital care in the private sector, the fee-for-service scheme does not provide incentives for patient selection.

Thanks to their coverage, the French elderly do not face financial constraints which could limit their access to health care. In addition, since they have been well covered their whole lives, there is no reason why health care expenditures should rise at a particular age. Such a rise could be observed in the US, where people can delay care until they become eligible for Medicare at 65 . Being continuous over the lifetime, coverage in France is unlikely to influence the profile of health expenditures by age group.

\subsection{Descriptive analysis}

3,441 individuals are observed in 1992 and 5,003 in 2000. We chose not to remove outliers from the data: removing the individuals who incurred the highest expenditures would jeopardize the representativity of the sample, especially for hospital expenditures.

Individual expenditure is explained by the participation rate and by the conditional expenditure i.e. expenditure observed for users. Graphs 2a-i show for each type of expenditure (physician visits, medication and hospital expenditures) the age profile of participation rate, conditional expenditure and unconditional expenditure. The participation rates of physician visits and pharmaceutical expenditures are high in 1992 and 2000 for all age groups (around 90\%). The observed change in the participation profile has therefore a small impact on the unconditional expenditure. For these expenditures, the conditional and unconditional expenditures profiles are very similar (see graphs $2 \mathrm{e}$ and $2 \mathrm{f}$ ). This is not the same for hospital expenditures, for which the participation rate is quite low (between 10\% and 20\%): changes in the participation profile have a greater impact on the final profile, which shows a sizeable drift between 1992 and 2000 for people age 50 and over. These features show that ambulatory care and hospital care need separate analyses. It is an advantage of our data 
to make it possible to consider them separately.

For physician and pharmaceutical expenditures, the profile (conditional and unconditional) is clearly increasing with age. A noticeable upward drift of this profile appears for people age 40 and over between 1992 and 2000. The drift is spectacular and significant $(\mathrm{p}<0.0001)$ for pharmaceutical expenditures, whereas it appears to be non significant $(\mathrm{p}=0.22)$ for physician consultations. To check for the significance of the drifts observed in the profiles, global significance tests have been carried out, as well as separate tests for each age group. Results are provided below graphs 2a-i : we give the age groups for which a significant drift is observed and the p-value of the global significance test. 
Graphs 2: HCE participation and expenditures profiles, adjusted for inflation

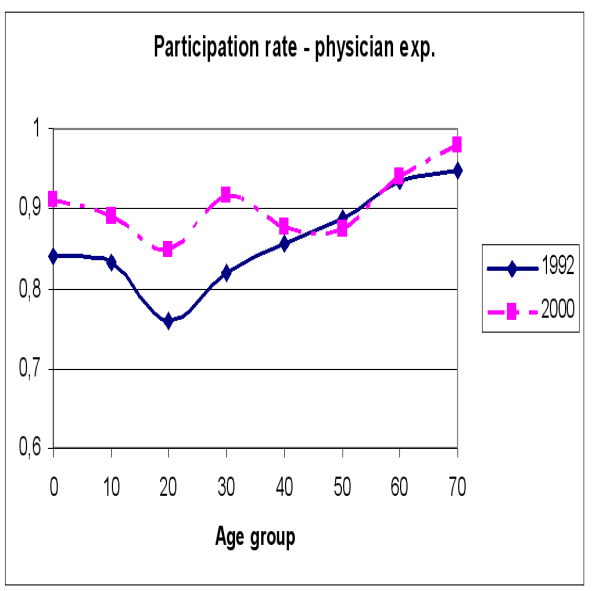

(2a) Sign. drift (5\%): 0, 10, 20, 30

$$
\mathrm{p}=0.0000
$$

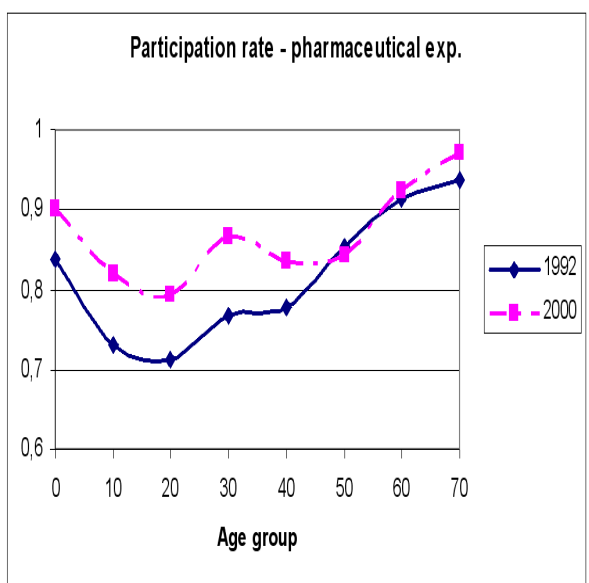

(2d) Sign. drift (5\%): 0, 10, 20, 30, 40

$$
\mathrm{p}=0.0000
$$

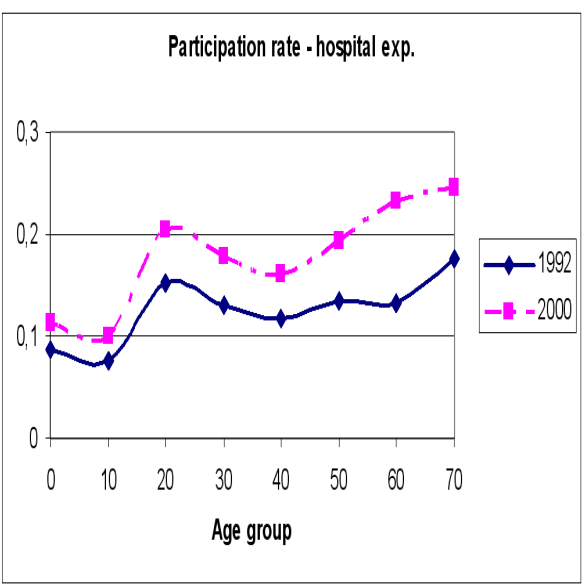

(2g) Sign. drift (5\%): 20, 30, 40, 50, 60 $\mathrm{p}=0.0000$
Conditional physician exp.

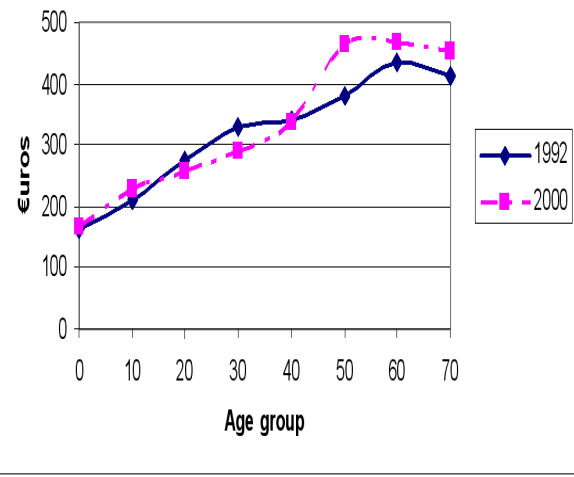

(2b) Sign. drift (5\%): 50

$\mathrm{p}=0.1201$

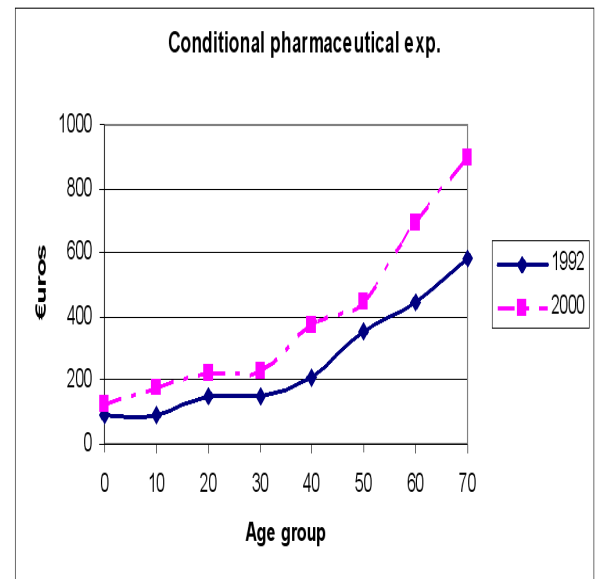

(2e) Sign. drift (5\%): 40, 60, 70

$\mathrm{p}=0.0000$

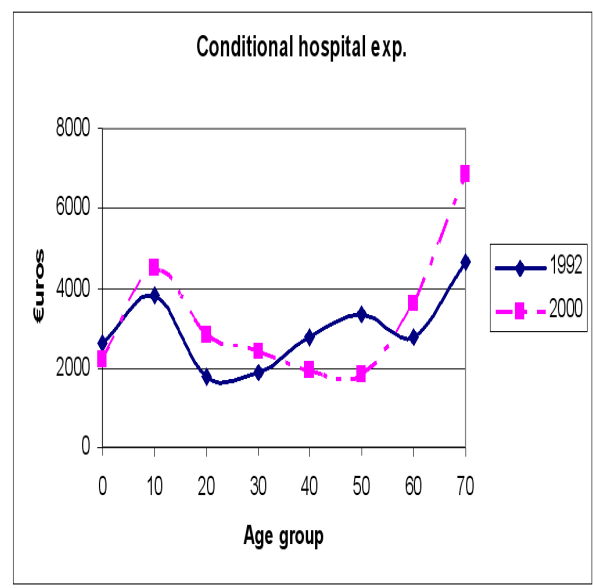

(2h) Sign. drift (5\%): none

$\mathrm{p}=0.5370$
Unconditional physician exp.

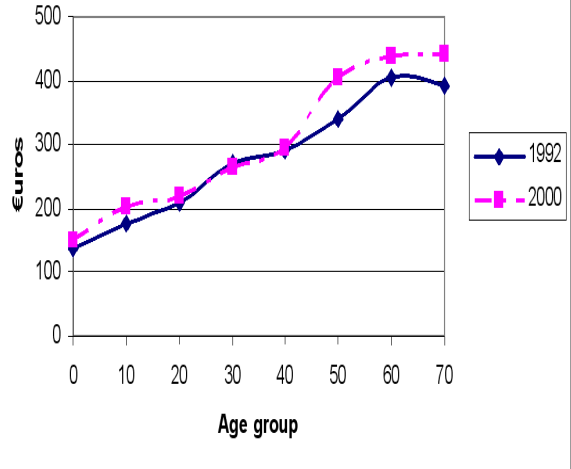

(2c) Sign. drift (5\%): 50

$\mathrm{p}=0.2253$

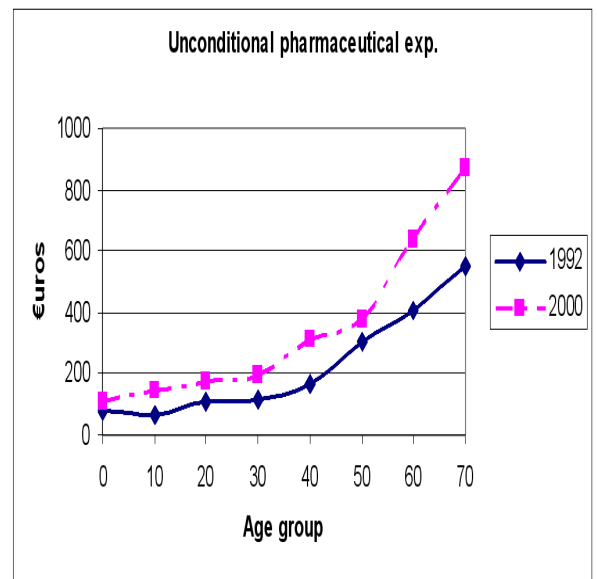

(2f) Sign. drift (5\%): 10, 30, 40, 60, 70 $\mathrm{p}=0.0000$

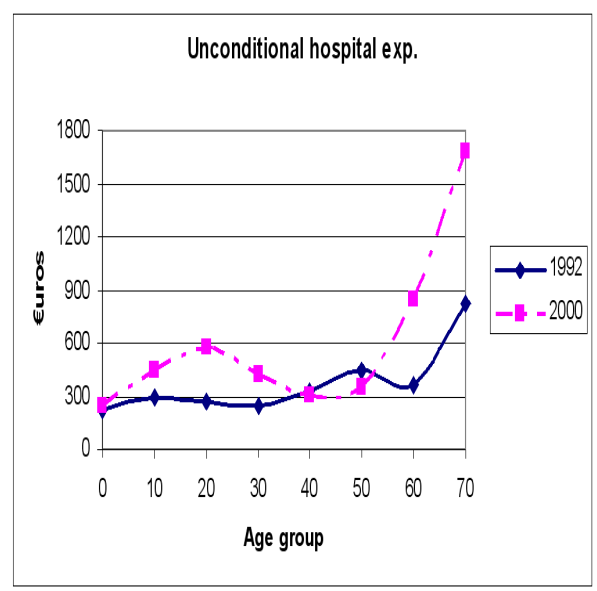

(2i) Sign. drift (5\%): 60, 70 $\mathrm{p}=0.0057$ 
No general upward drift is clearly noticeable for hospital expenditures (conditional and unconditional) but a drift for people age 60 and over is observed (graph 2i). Participation rate for hospital care has dramatically increased between 1992 and 2000, for all age groups (the drift is significant for each age group). This rise in participation explains the shape of the unconditional expenditures profiles: the corresponding drift is significant $(\mathrm{p}<0.0001$, due to age groups 60 and 70 and over) whereas the drift for conditional expenditures is not significant $(\mathrm{p}=0.54)$.

The hospital expenditure profile is relatively flat until the 50-59 age group, then becomes very sloping. In a very enlightening descriptive analysis, Yang et al. [41] show that the age profile of Medicare expenditures (which are mainly determined by hospital costs) is strongly influenced by the costs incurred by people who deceased within the year: when separating "decedents" and "survivors", the slope of the age profile for survivors is far less steep. It is thus of major importance to check whether the steep profile we observe for the aged is not only due to people dying in hospital. Our data allow us to know whether people observed in 2000 have survived until 2004. Graph 2j displayed below shows hospital and pharmaceutical expenditure profiles for all individuals in 2000 and for survivors only (still alive in 2004). The slope is less steep, but still noticeable for survivors. Therefore, the shape of the hospital expenditure profile is not only due to decedents. Interestingly, the steepening of hospital expenditure profile begins with age group 60, whereas the pharmaceutical profile slope is increasing from its very beginning (even for survivors).

\section{Results}

\subsection{The estimates}

The estimation of equations (1) and (2) reveals a strong influence of morbidity on participation and conditional consumption (detailed results are provided for pharmaceutical expenditures in the appendix, while the other results are available on request). Several morbidity indicators, the number of diseases and the levels of disability and death risk have large positive impacts on the use of health care services. To take an example, in 1992, a disability level equal to 3 (i.e. a situation where the individual "experiences difficulties but lives normally") incurs an increase in conditional pharmaceutical consumption of $42 \%$. When the disability level is equal to 4 or 5 , the rise in the conditional pharmaceutical consumption amounts to $77 \%$ and $89 \%$ (level 4 is the situation where the individual "must diminish his/her domestic or professional activity", level 5 encompasses situations 


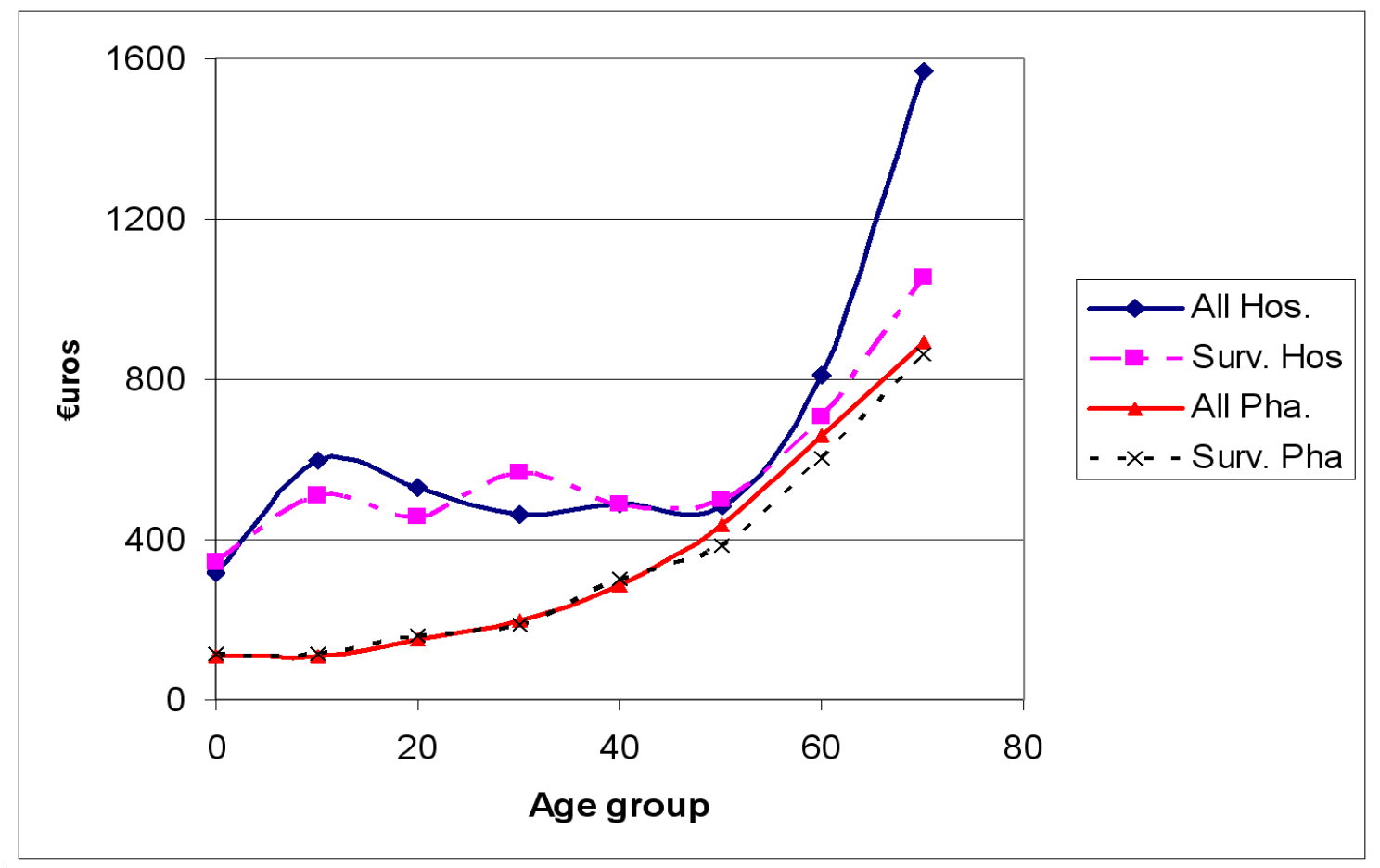

Graph 2j : Hospital and pharmaceutical expenditures (year 2000) of all vs. survivors until 2004

where the individual "has diminished activity", "has no domestic autonomy" or "is confined to bed"). The conditional pharmaceutical consumption is also strongly influenced by hypertension $(+40 \%)$, diabetes $(+48 \%)$ trouble with lipid metabolism $(+26 \%)$ and depression $(+37 \%)$ (these figures are given for the 1992 estimates). Participations to consultation and pharmaceutical consumption (see table 3 in the appendix) are also significantly influenced by our morbidity indicators. The conditional consultation expenditure is positively influenced by depression $(+27 \%)$ and the number of diseases. Turning to hospital expenditure, participation appears to be positively influenced by diabetes, death risk and cataract, and conditional expenditure by the level of disability and hypertension $(+37 \%)$.

Otherwise, we find that the absence of privately subscribed complementary coverage significantly reduces participation and consumption of ambulatory care. For example, in 1992, the drop amounts to $-39 \%$ for conditional physician expenditures and to - $25 \%$ for conditional pharmaceutical expenditures. On the other hand, complementary coverage has no significant influence on the use of hospital care. This is not surprising. Indeed, participation to hospital care does not result from an individual decision and the complementary insurance does not add any substantial coverage for hospital care (see 3.2). In general, gender is not significant for participation, but being a female increases consultation and pharmaceutical expenditures by about $17 \%$. Gender is not significant for hospital 
expenditures.

As stated above, changes in practices for a given morbidity are captured with changes in the estimated coefficients of morbidity indicators between 1992 and 2000. Our results show that for conditional expenditures, most of the positive coefficients estimated for the various morbidity indicators are larger in 2000 than in 1992 (for pharmaceutical conditional expenditures - see table 2 in the appendix - this is observed for hypertension, trouble with lipid metabolism, self-assessed health and disability levels 2 to 5). The impact of changes in practices that we compute is the total effect on expenditure resulting from the changes that occured on the coefficients of the morbidity indicators. Not all the coefficients of morbidity indicators do increase between 1992 and 2000. However, their total effect might incur an increased level of expenditures. As shown below, our conjecture is validated by the microsimulation results: for a given morbidity condition, expenditures are higher in 2000 than in 1992.

The increasing shape of the age profile of expenditure is entirely due to the fact that morbidity is increasing with age [27]. However, it is not straightforward to assess the influence on expenditure growth of changes in morbidity. Indeed, these changes are not uniform: improvements or deteriorations can be observed, depending on the age group considered. This is illustrated by the following graph, which represents the prevalence of diabetes per age group. It does not allow us to draw any clear-cut conclusion about a general improvement nor deterioration of health status between 1992 and 2000, and hence about its consequences on expenditures. Indeed, the prevalence of diabetes decreases below the age of 69, and increases for people aged 70 and more. Neither do the age profiles of our various morbidity indicators highlight a clear-cut change of prevalence or health status in general. Our simulation method enables us to evaluate, for all the morbidity and disability indicators taken as a whole, the total effect of all these various changes. 


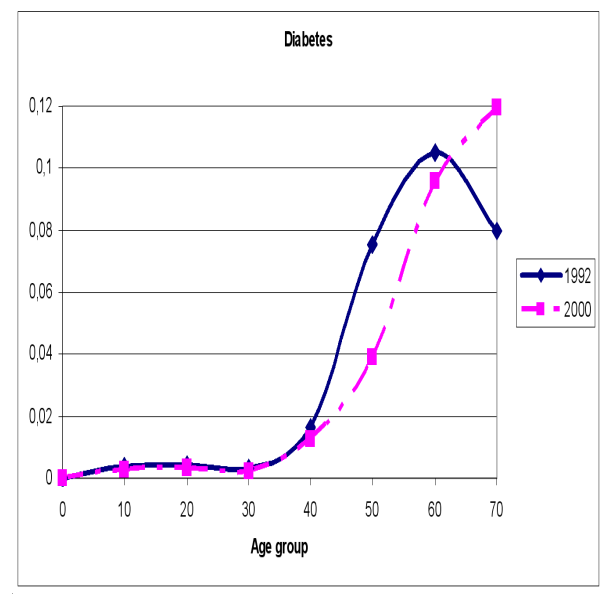

To sum up, our microsimulation method makes it possible to evaluate the total effects of multidimensional changes, both in practices and in morbidity.

\subsection{Microsimulations: identifying the impacts of changes in practices and morbidity}

Our simulations led to the calculation of average probability of participation and average conditional expenditures for each age group $j$, at each step of the reasoning. Namely, the values $\hat{\pi}_{. j}^{92.92}, \hat{\pi}_{. j}^{m 92 . b 00}$, $\stackrel{\wedge}{\pi}_{. j}^{m 00 . b 00}$ and $\stackrel{\wedge}{\pi}_{. j}^{00.00}$ for participation and $(C \mid P)_{. j}^{92.92},(C \mid P)_{. j}^{m 92 . b 00},(C \mid P)_{. j}^{m 00.600}$ and $(C \mid P)_{. j}^{00.00}$ for the conditional expenditures were computed. At each step of simulation, unconditional expenditure $C$ is computed as the product $\pi *(C \mid P)$. The resulting profiles by age group are displayed in graphs 3 a and $3 \mathrm{~b}$ for unconditional pharmaceutical and hospital expenditures. For each variable of interest, the drift between the profile of 1992 (profile 1) and the profile of 2000 (profile 4) is split into 3 incremental effects : $(i)$ the transition from profile 1 to profile 2 gives the effect of changes in practices for a given observable level of morbidity ; $(i i)$ the transition from profile 2 to profile 3 gives the effect of changes in morbidity ; ( iii) the transition from profile 3 to profile 4 gives the effect of other changes in behavior and individual characteristics. Ambulatory care (physician and pharmaceutical expenditures) and hospital expenditures show fairly different results, which are worth treating separately.

Our simulations led to the construction of 9 graphs, corresponding to participation, conditional and unconditional expenditures for the three types of expenditures. To simplify the presentation, we provide only two graphs relative to the pharmaceutical and hospital unconditional expenditures. Indeed changes in the age profile of the physician expenditures prove to be non significant between 1992 and 2000 (see 3.3). The reader interested by detailed results about simulations for participation 
and unconditional expenditures for drugs and hospital can refer to Dormont \& Huber [27].

\subsubsection{Ambulatory care}

For ambulatory care, the bulk of changes is essentially due to changes in expenditures conditional on participation and not to changes in participation. The latter have a very small influence because participation to ambulatory care is already high in 1992 and changes that occurred in 2000 are limited (see section 3.3).

The tremendous rise in pharmaceutical expenditures is clearly observable on graph 3a. Our simulations show that this large upward drift is almost entirely due to changes in practices for a given level of morbidity (profile 1 to 2 ). It means that for the level of morbidity they experienced in 1992, individuals would have spent more in 2000 than what they actually spent in 1992, whatever their age. Thus, changes in practices induce an increase in health care expenditures, for a given level of morbidity.

The changes in morbidity induce a downward drift (profile 2 to 3 ) for all age groups (except $70+$ ), which partly compensates the upward drift due to changes in practices. This downward drift means that changes in morbidity that occurred between 1992 and 2000 induced a decrease in health care expenditures at every age below 70, all other things being equal as regards practices. More thorough investigation would be needed in order to assess that health is indeed improving. What can be said however is that changes in health conditions have retrospectively led to savings.

The changes that occured for pharmaceutical expenditures are spectacular, by far much larger than what is observed for physician expenditures. Notice that, at the macroeconomic level, drugs are responsible for the bulk of the growth in total health care expenditures: they account for one fourth of total health care expenditures and their growth rate is more than twice as large as for physicians and hospital [27].

Our results show that for drugs the drift in the age profile is entirely due to changes in practices, for a given level of morbidity. It is not due to changes in the behavior of the elderly on the demand side. Indeed, changes in participation have a negligible influence and the level of consumption derives from prescriptions (it is the doctor's decision). There is a large innovation component on the supply side: changes are likely to be connected with the supply of new products on the health care market. 


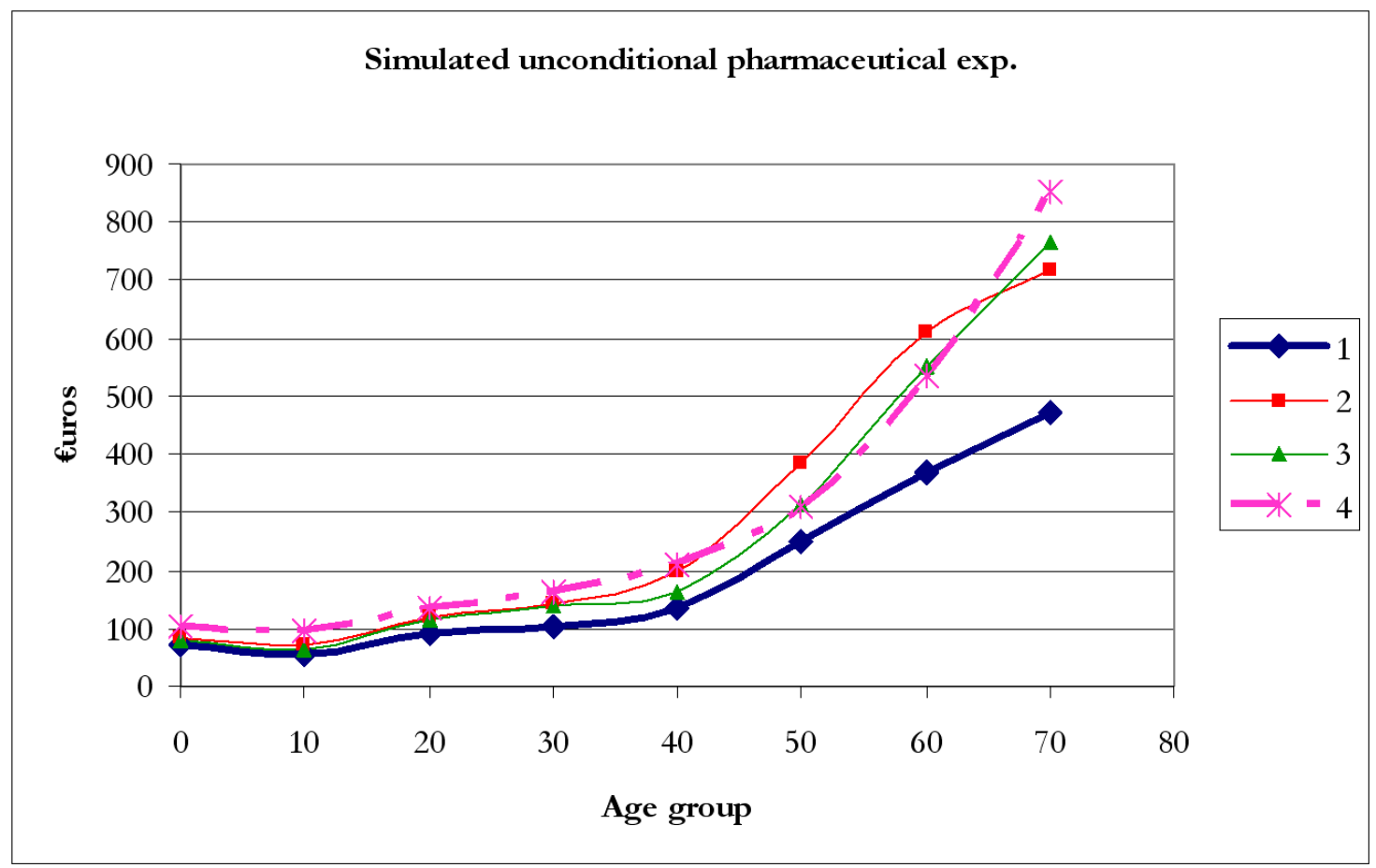

Graph 3a : Simulated unconditional pharmaceutical expenditures

\subsubsection{Hospital}

For hospital unconditional expenditures, we find again the positive effect of changes in practices for a given morbidity (profile 1 to 2) as well as the negative effect of changes in morbidity (profile 2 to 3). These changes are observed only for people age 40 and over (graph 3b). The drift observed for the two last age groups is due to the combined effects of changes in practices and "other changes".

What is observed for hospital care contrasts strongly with ambulatory care, in the sense that changes in the unconditional expenditure are mainly due to a drift in the participation profile. The drift in participation rates is observed for every age group and is increasing with age (see graph $2 \mathrm{~g}$ ). Our simulation shows that this upward drift is due firstly to the "other changes" and secondly to changes in practices for a given level of morbidity, along with a slight downward drift due to the changes in morbidity. 


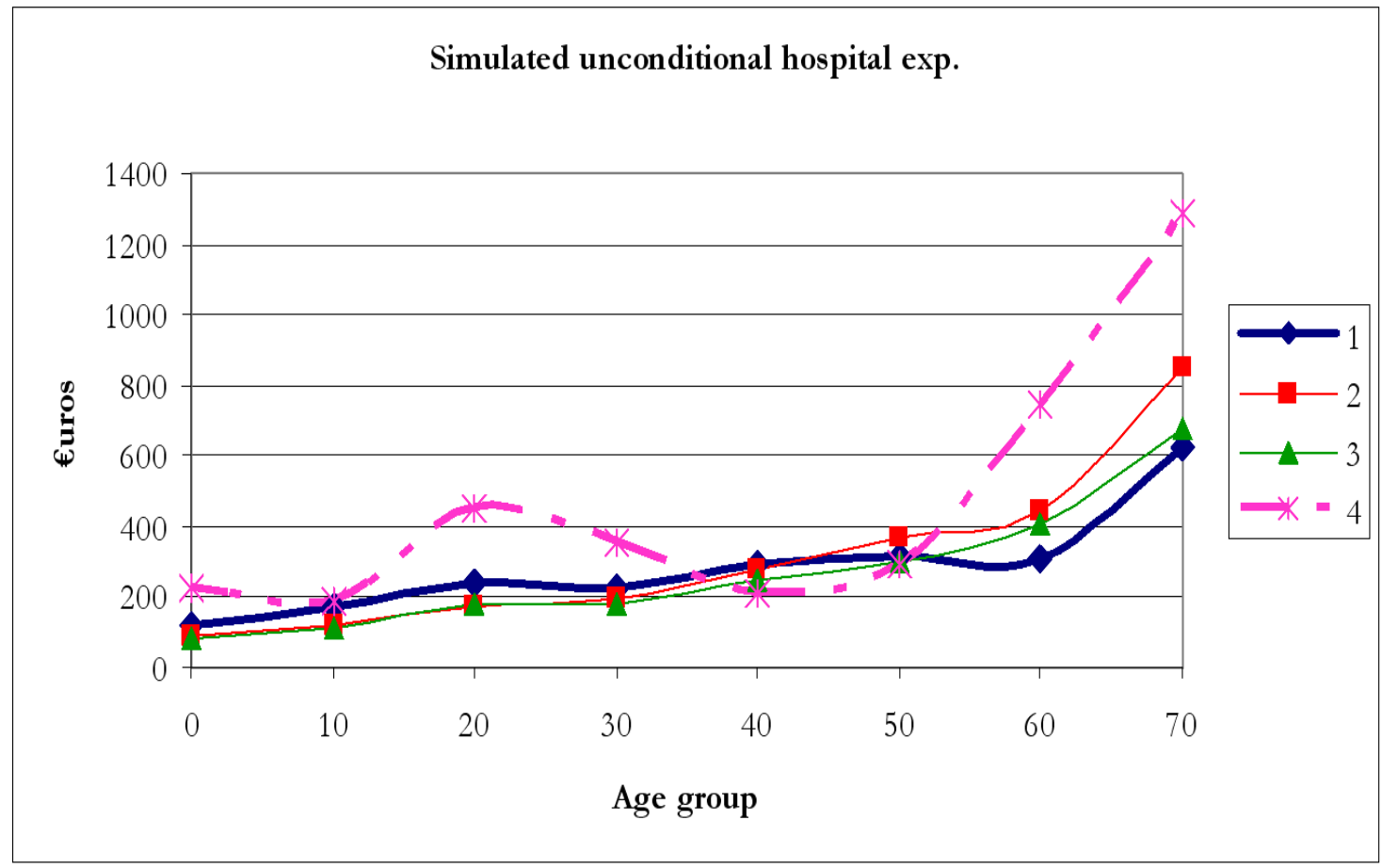

Graph 3b : Simulated unconditional hospital expenditures

\section{Conclusion: assessing the pure demographic effect at the macro level}

The microsimulations performed above have enabled us to identify the components of the profile drifts observed between 1992 and 2000, i.e. what is due to changes in practices and what is due to changes in morbidity. Our simulated profiles can be applied to the structure by age of the French population. This leads to an assessment of the relative effects of demographic change and profile drifts for the period 1992-2000 at the aggregate level.

Results are provided in table 1. The total demographic effect is computed assuming that the 1992 age profile of expenditures is held constant, and that only the structure and size of the population changed over time. The other effects are then computed by using the different simulated profiles. A bootstrap analysis has been performed to assess the significance of these results (bootstrap by pairs, 800 replications).

The rise in health care expenditures due to demographic change appears to be very small in comparison with the effects of changes in practices. For total expenditures, we find that the impact of changes in practices is equal to $+12.9 \%$, which is 3.8 times more than the rise in health care 
expenditures due to changes in the age structure of the population $(+3.4 \%)$.

The aggregate effect of changes in morbidity appears to be negative for each type of health expenditure, indicating health improvements of individuals for a given age between 1992 and 2000 . For total expenditure, this negative effect of changes in morbidity $(-9.7 \%)$ more than offsets the positive shock due to changes in the age structure of the population $(+3.4 \%)$. This is also true for pharmaceutical and hospital expenditures.

\begin{tabular}{r|r|r|r|r} 
Variation 1992-2000 (\%) & Physicians & Pharmac. & Hospital & Total \\
Total demographic change & 5,05 & 7,63 & 6,37 & 6,35 \\
of which : & & & & \\
part of structural change & 2,10 & 4,61 & 3,38 & 3,36 \\
part of growing size of population & 2,95 & 3,02 & 2,99 & 2,99 \\
Changes in morbidity & $-1,23$ & $-9,24$ & $-14,61$ & $-9,74$ \\
Changes in age dummies & 28,63 & 14,11 & $-26,25$ & $-1,55$ \\
Other changes & $-2,80$ & 2,53 & 95,51 & 45,95 \\
\hline Total variation 1992-2000 (\%) & 14,57 & 67,27 & 68,08 & 53,89 \\
& & & &
\end{tabular}

Table 1 : Simulations at the macro level

Our results show that ageing explains only a small part of the rise in health care expenditures. Changes in practices for a given morbidity are by far a more important driver. For ambulatory care, changes in practices are not linked to changes in participation behavior but to changes in conditional consumption. The drift due to changes in practices is spectacular for pharmaceutical expenditures, suggesting a large innovation component. These results reveal that the drifts we observe are not due to demand side changes in behavior.

We have considered a separate specification for participation. This allows us to isolate changes that can be due to patients' initiative, whose magnitude proved to be negligible. 
Our data allow us to split health care expenditures into three components. Since we have separate information on pharmaceutical expenditures, we are able to show that the upward drift in drug consumption is mainly due to the supply side, i.e. to technological progress. Our database also has the great advantage of providing detailed information about morbidity, while numerous papers of the literature devoted to ageing are based on rather poor information about morbidity, often reduced to a single indicator, i.e. time to death.

We set up an original microsimulation method to exploit the richness of our multidimensional information about morbidity. This allows us : (i) to provide empirical evidence of global health improvement (ii) to evaluate the savings due to changes in morbidity. Health care expenditures are often conceived of as a burden and it is indeed very difficult to measure their benefits. Our findings give evidence of health improvements. These results deserve further investigation: given the size of our sample, the number of observations is rather small as regards people age 80 and over. Implementing the same method on larger samples should give a better assessment of changes that affect morbidity for this age group.

Our microsimulation method makes it possible to identify the different components of the growth in health care expenditures. If this methodology were applied to data on other countries, it could be used to measure the effects of various forms of regulation of health care systems on expenditure growth and access to care at different ages.

In the case of France, we have shown that changes in practices appear to be the main driver in the increase in expenditures. It is possible that technological progress is oriented towards the elderly more than other age groups. In that case, the impact of changes in practices would increase with age. Due to our data limitations, we were not able to estimate slopes specific to each age group in order to study this question. Further investigation with larger samples will allow us to study the pattern of technological progress diffusion more thoroughly. 


\section{Appendix: pharmaceutical expenditures estimates}

Table 2 - GLM Consumption Equation : Pharmaceutical expenditures, 1992 and 2000

\begin{tabular}{|c|c|c|c|c|c|c|}
\hline & 1992 & Obs: 2745$)$ & & 2000 & (Obs: 4307) & \\
\hline Var & Coef. & Std. Err. & $\mathrm{P}>\mathrm{z}$ & Coef. & Std. Err. & $\mathrm{P}>\mathrm{z}$ \\
\hline age $0-9$ & 5.829 & 0.170 & 0.000 & 5.995 & 0.311 & 0.000 \\
\hline age $10-19$ & 5.594 & 0.189 & 0.000 & 5.970 & 0.341 & 0.000 \\
\hline age $20-29$ & 5.833 & 0.186 & 0.000 & 5.948 & 0.327 & 0.000 \\
\hline age $30-39$ & 5.814 & 0.188 & 0.000 & 5.924 & 0.328 & 0.000 \\
\hline age $40-49$ & 5.749 & 0.183 & 0.000 & 5.980 & 0.324 & 0.000 \\
\hline age $50-59$ & 5.843 & 0.181 & 0.000 & 5.904 & 0.326 & 0.000 \\
\hline age $60-69$ & 5.927 & 0.183 & 0.000 & 5.888 & 0.331 & 0.000 \\
\hline age $70+$ & 5.955 & 0.191 & 0.000 & 6.010 & 0.333 & 0.000 \\
\hline female & 0.178 & 0.039 & 0.000 & 0.237 & 0.070 & 0.001 \\
\hline school: never & - & - & - & - & - & - \\
\hline school: primary & -0.298 & 0.089 & 0.001 & -0.341 & 0.139 & 0.014 \\
\hline school: junior high & -0.171 & 0.101 & 0.089 & -0.240 & 0.162 & 0.138 \\
\hline school: high school & -0.233 & 0.110 & 0.034 & -0.385 & 0.174 & 0.027 \\
\hline school: higher educ & -0.276 & 0.115 & 0.017 & -0.301 & 0.175 & 0.085 \\
\hline household size & -0.032 & 0.017 & 0.057 & -0.037 & 0.030 & 0.215 \\
\hline diabetes & 0.481 & 0.113 & 0.000 & 0.206 & 0.221 & 0.351 \\
\hline hypertension & 0.401 & 0.071 & 0.000 & 0.528 & 0.123 & 0.000 \\
\hline lipid & 0.259 & 0.089 & 0.003 & 0.409 & 0.149 & 0.006 \\
\hline depression & 0.373 & 0.083 & 0.000 & 0.025 & 0.157 & 0.875 \\
\hline arthro-dorso & -0.100 & 0.060 & 0.095 & -0.448 & 0.101 & 0.000 \\
\hline nb diseases & 0.062 & 0.012 & 0.000 & 0.047 & 0.022 & 0.032 \\
\hline Self-Assessed Health & -0.129 & 0.014 & 0.000 & -0.121 & 0.027 & 0.000 \\
\hline disab 0 & - & - & - & - & - & - \\
\hline disab 1 & -0.014 & 0.075 & 0.856 & 0.024 & 0.126 & 0.851 \\
\hline disab 2 & 0.203 & 0.084 & 0.016 & 0.415 & 0.121 & 0.001 \\
\hline disab 3 & 0.418 & 0.092 & 0.000 & 1.135 & 0.143 & 0.000 \\
\hline disab 4 & 0.768 & 0.111 & 0.000 & 1.655 & 0.182 & 0.000 \\
\hline disab 5 & 0.886 & 0.161 & 0.000 & 1.390 & 0.272 & 0.000 \\
\hline No compl cov & -0.250 & 0.065 & 0.000 & -0.035 & 0.116 & 0.760 \\
\hline
\end{tabular}

Test of global significancy of the model: $p<0.0000$ for years 1992 and 2000 . 
Table 3 - Probit Participation Equation : Pharmaceutical expenditures, 1992 and 2000

\begin{tabular}{|c|c|c|c|c|c|c|}
\hline & 1992 & Obs: 3441$)$ & & 2000 & Obs: 5003) & \\
\hline Var & Coef. & Std. Err. & $\mathrm{P}>\mathrm{z}$ & Coef. & Std. Err. & $\mathrm{P}>\mathrm{z}$ \\
\hline age $0-9$ & 2.304 & 0.273 & 0.000 & 2.459 & 0.260 & 0.000 \\
\hline age $10-19$ & 1.829 & 0.287 & 0.000 & 1.934 & 0.268 & 0.000 \\
\hline age $20-29$ & 1.509 & 0.263 & 0.000 & 1.595 & 0.249 & 0.000 \\
\hline age $30-39$ & 1.459 & 0.256 & 0.000 & 1.647 & 0.242 & 0.000 \\
\hline age $40-49$ & 1.368 & 0.253 & 0.000 & 1.388 & 0.239 & 0.000 \\
\hline age $50-59$ & 1.367 & 0.254 & 0.000 & 1.197 & 0.239 & 0.000 \\
\hline age $60-69$ & 1.494 & 0.264 & 0.000 & 1.452 & 0.247 & 0.000 \\
\hline age $70+$ & 1.620 & 0.297 & 0.000 & 1.788 & 0.279 & 0.000 \\
\hline diabetes & 0.560 & 0.281 & 0.046 & 0.205 & 0.245 & 0.403 \\
\hline hypertension & 0.442 & 0.143 & 0.002 & 0.422 & 0.128 & 0.001 \\
\hline lipid & 0.596 & 0.219 & 0.006 & 0.344 & 0.167 & 0.039 \\
\hline arthro-dorso & 0.264 & 0.098 & 0.007 & 0.133 & 0.075 & 0.075 \\
\hline nb diseases & 0.039 & 0.016 & 0.018 & 0.073 & 0.016 & 0.000 \\
\hline Self-Assessed Health & -0.039 & 0.020 & 0.055 & -0.043 & 0.020 & 0.032 \\
\hline female & 0.099 & 0.053 & 0.061 & 0.160 & 0.048 & 0.001 \\
\hline soc: farmers & -0.070 & 0.241 & 0.772 & -0.068 & 0.194 & 0.725 \\
\hline soc: indep. & 0.108 & 0.123 & 0.379 & -0.364 & 0.098 & 0.000 \\
\hline soc: intell. & 0.003 & 0.100 & 0.977 & 0.001 & 0.075 & 0.992 \\
\hline soc: interm. & 0.290 & 0.072 & 0.000 & 0.071 & 0.071 & 0.318 \\
\hline soc: clerks & 0.136 & 0.082 & 0.096 & 0.012 & 0.079 & 0.881 \\
\hline soc: qual. & - & - & - & - & - & - \\
\hline soc: non-qual. & 0.174 & 0.096 & 0.070 & 0.018 & 0.090 & 0.842 \\
\hline school: never & - & - & - & - & - & - \\
\hline school: primary & -0.305 & 0.131 & 0.020 & -0.353 & 0.119 & 0.003 \\
\hline school: junior high & -0.136 & 0.143 & 0.343 & -0.169 & 0.128 & 0.185 \\
\hline school: high school & -0.252 & 0.155 & 0.104 & -0.114 & 0.137 & 0.406 \\
\hline school: higher educ & -0.448 & 0.162 & 0.006 & -0.438 & 0.138 & 0.001 \\
\hline matrim: married & - & - & - & - & - & - \\
\hline matrim: divorced & 0.105 & 0.185 & 0.570 & 0.095 & 0.137 & 0.488 \\
\hline matrim: widow & -0.007 & 0.200 & 0.973 & -0.090 & 0.184 & 0.625 \\
\hline matrim: single & -0.417 & 0.093 & 0.000 & -0.409 & 0.083 & 0.000 \\
\hline Household size & -0.100 & 0.021 & 0.000 & -0.034 & 0.020 & 0.083 \\
\hline No compl cov & -0.403 & 0.076 & 0.000 & -0.359 & 0.071 & 0.000 \\
\hline
\end{tabular}

Test of global significancy of the model: $p<0.0000$ for years 1992 and 2000 . 


\section{References}

[1] Bac C. and Cornilleau G. Comparaison internationale des dépenses de santé : une analyse des évolutions dans sept pays depuis 1970. Etudes et Résultats, DREES, 175, 2002.

[2] Gerdtham U. G., Sogaard J., Andersson F., and Jonsson B. An econometric analysis of health care expenditure: a cross-section study of the OECD countries. Journal of Health Economics, 11:63-84, 1992.

[3] Gerdtham U. G., Jonsson B., MacFarlan M., and Oxley H. Health, the medical profession and regulation, chapter The determinants of health expenditure in the OECD countries : a pooled data analysis, pages 113-134. Kluwer Academic Publisher, 1998.

[4] Getzen T. E. Population aging and the growth of health care expenditures. Journal of Gerontology, 47:S98-S104, 1992.

[5] Hitiris T. and Posnett J. The determinants and effects of health expenditure in developed countries. Journal of Health Economics, 11:173-181, 1992.

[6] Leu R. E. Public and private health services : complementarities and conflicts, chapter The public-private mix and international health care costs, pages 41-63. Blackwell Scientific Publications, 1986.

[7] O'Connell J. The relationship between health expenditures and the age structure of the population in OECD countries. Health Economics, 5:573-578, 1996.

[8] OECD. Financing and delivering health care : a comparative analysis of OECD countries, 1987.

[9] Zweifel P., Felder S., and Meiers M. Ageing of the population and health care expenditure : a red herring? Health Economics, 8:485-496, 1999.

[10] Seshamani M. and Gray A. M. A longitudinal study of the effects of age and time to death on hospital costs. Journal of Health Economics, 23:217-235, 2004.

[11] Seshamani M. and Gray A. M. Aging and health-care expenditure : the red herring argument revisited. Health Economics, 13:303-314, 2004.

[12] Zweifel P., Felder S., and Werblow A. Population aging and health care expenditures : new evidence on the red herring. The Geneva papers on risk and insurance, 29(4), october 2004.

[13] Stearns S. C. and Norton E. C. Time to include time to death ? the future of health care expenditure predictions. Health Economics, 13:315-327, 2004.

[14] OECD. Projecting oecd health and long-term care expenditures: what are the main drivers ?, 2006. OECD economics department working papers.

[15] Denton F.T., Gafni A., and Spencer B.G. Exploring the effects of population change on the costs of physician services. Journal of Health Economics, 21, 2002.

[16] Grignon M. Impact macro-économique du vieillissement de la population sur les dépenses d'assurance-maladie en France. Santé Société et Solidarité, 2:135-154, 2002. 
[17] Grunenberg E.M. The failure of success. Milbank Memorial Fund Q. Health Soc., 55:3-24, 1977.

[18] Fries J.F. Ageing, natural death, and the compression of morbidity. New England Journal of Medicine, 303:130$135,1980$.

[19] Michel J-P and Robine J-M. A 'new' general theory of population ageing. Geneva Papers on Risk and Insurance: Issues and Practice, 29(4):667-678, October 2004.

[20] Cutler D.M. The Potential For Cost Savings In Medicare's Future. Health Affairs, page hlthaff.w5.r77, 2005. http://content.healthaffairs.org/cgi/content/abstract/hlthaff.w5.r77v1.

[21] Lubitz J. Health, Technology, And Medical Care Spending. Health Affairs, page hlthaff.w5.r81, 2005. http://content.healthaffairs.org/cgi/content/abstract/hlthaff.w5.r81v1.

[22] Evans R.G., McGrail K.M., Morgan S.G., Barer M.L., and Hertzman C. Apocalypse no: population aging and the future of health care systems. SEDAP Research paper vol. 59, http://socserv2.mcmaster.ca/sedap, october 2001.

[23] Cutler D.M. and Huckman R.S. Technological development and medical productivity: the diffusion of angioplasty in New York State. Journal of Health Economics, 22(2):187-217, 2003.

[24] Cutler D. and McClellan M. The determinants of technological change in heart attack treatment. NBER Working Paper, (5751), 1996.

[25] Manning W. G. and Mullahy J. Estimating log models : to transform or not to transform ? Journal of Health Economics, 20:461-494, 2001.

[26] Chernichovsky D. and Markowitz S. Aging and aggregate costs of medical care: conceptual and policy issues. Health Economics, 13:543-562, 2004.

[27] Dormont B. and Huber H. Causes of health expenditures growth: the predominance of changes in medical practices over population ageing, February 2006. LEGOS-Université Paris-Dauphine Working Paper http://www.dauphine.fr/eurisco/eur_cr/cah0603.pdf.

[28] Salas C. and Raftery J.P. Econometric issues in testing the age neutrality of health care expenditures. Health Economics, 10:669-671, 2001.

[29] Baubeau D., Bousquet F., and Joubert M. Le traitement chirurgical de la cataracte en France. Etudes et Résultats, DREES, 101, 2001.

[30] Oberlin Ph., Mouquet M.-C., and Folliguet Th. Le traitement invasif des maladies coronariennes. Etudes et Résultats, DREES, 289, february 2004.

[31] The Technological Change in Health Care Research Network (TECH). Technological change around the world: Evidence from heart attack care. Health Affairs, 20(3):25-42, 2001.

[32] Oaxaca R. Male-female wage differentials in urban labor markets. International Economic Review, 14:693-709, 1973. 
[33] Bourguignon F., Ferreira F. H. G., and Leite P.G. Beyond Oaxaca-Blinder: Accounting for differences in household income distribution across countries, 2002. DELTA Working Paper.

[34] Dormont B. and Milcent C. Innovation diffusion under budget constraints. microeconometric evidence on heart attack in france, 2005. Annales d'Economie et de Statistique 5-6, forthcoming.

[35] Heckman J. J. Sample selection bias as a specification error. Econometrica, 47:153-161, 1979.

[36] Dow W. H. and Norton E. C. The red herring that eats cake : Heckit versus two-part model redux, February 2002. Triangle health economics working paper series - www.unc.edu/the.

[37] Leung S. F. and Yu S. On the choice between sample selection and two-part models. Journal of Econometrics, 72:197-229, 1996.

[38] Manning W., Duan N., and Rogers W. Monte carlo evidence on the choice between sample selection and two-part models. Journal of Econometrics, 35:59-82, 1987.

[39] Staiger D. and Stock JH. Instrumental variables regression with weak instruments. Econometrica, 65:557-586.

[40] IRDES Institute Paris France. Eco-Santé 2002 Database.

[41] Yang Z., Norton E.C., and Stearns S.C. The real reasons older people spend more. Journal of Gerontology : Social Sciences, 58B(1):S1-S10. 